$10 \mathrm{mg} / \mathrm{kg}$ (2 patients) or by shortening the infusion intervals to 4 weeks (2 patients) along with the addition of corticosteroids or immunosuppressives. In the remaining 7 patients IFX was switched to another agent (cyclophosphamide in 5 , adalimumab in 1 and anakinra in 1). At the time of this survey $8 / 17$ patients were still on IFX for a mean follow-up of $32.5 \pm 24.6$ (SD) months, with concomitant low dose prednisolone in 5, azathioprine in 3 and mycophenolate mofetil in 3 . In addition to the 7 patients who discontinued IFX at the time of de-novo manifestations, 2 more patients had discontinued IFX due to allergic reactions.

Conclusion: De novo manifestations developed during IFX treatment in $6 \%$ of BS patients, despite efficacy for the initial manifestation. Appearance of de novo manifestations mostly in patients with vascular involvement is noteworthy. Intensification of IFX treatment was efficacious in managing de novo manifestations in more than half of these patients.

REFERENCES:

[1] Hamuryudan V et al. Semin Arthritis Rheum. 2015;45(3):369-73.

Table 1. Distribution of de novo manifestations that have emerged in 17 patients

\begin{tabular}{lc}
\hline De-novo manifestations & $\mathbf{2 1}$ \\
\hline Pulmonary artery aneurysm & 1 \\
Pulmonary artery thrombosis & 2 \\
Coronary artery involvement & 3 \\
Superficial thrombophlebitis & 5 \\
Arthritis & 5 \\
Erythema nodosum & 3 \\
Gastrointestinal involvement & 1 \\
Central nervous system involvement & 1
\end{tabular}

Disclosure of Interests: None declared

DOI: 10.1136/annrheumdis-2021-eular.3887

\section{POS0820 INFLIXIMAB FOR VASCULAR INVOLVEMENT IN BEHÇET SYNDROME}

G. Hatemi ${ }^{1,2}$, B. Tukek ${ }^{3}$, S. N. Esatoglu ${ }^{1,2}$, Y. Ozguler ${ }^{1,2}$, M. Melikoglu ${ }^{1,2}$, E. B. Caliskan ${ }^{3}$, S. Ugurlu ${ }^{1,2}$, I. Fresko ${ }^{1,2}$, S. Yurdakul ${ }^{1,2}$, H. Yazici ${ }^{1,2}$, V. Hamuryudan ${ }^{1,2} .{ }^{1}$ Istanbul University - Cerrahpasa, Cerrahpasa Medical Faculty, Department of Internal Medicine, Division of Rheumatology, Istanbul, Turkey; ${ }^{2}$ Istanbul University - Cerrahpasa, Cerrahpasa Medical
Faculty, Behcet Disease Center, Istanbul, Turkey; ${ }^{3}$ Istanbul University Cerrahpasa, Cerrahpasa Medical Faculty, Department of Internal Medicine, Istanbul, Turkey

Background: Vascular involvement is an important cause of morbidity and mortality in patients with Behçet syndrome (BS). TNF inhibitors have been reported to be effective for almost all serious manifestations of BS but data on vascular involvement is still limited.

Objectives: To survey the efficacy and safety of infliximab (IFX) in BS patients with vascular involvement followed in a dedicated tertiary center.

Methods: We reviewed the charts of all BS patients who used IFX and identified those who used this drug for vascular involvement. A standard form was used for extracting data on demographic and clinical features, type of vascular involvement, concomitant immunosuppressives, duration of IFX use, relapses, adverse events and outcome.

Results: 83 patients ( 67 men, 16 women, mean age $39.5 \pm 8.4$ SD years) had used IFX for vascular involvement. The number of patients with each type of vascular involvement as the main indication for IFX, and previous treatment modalities right before IFX are presented in the Table 1. 33 patients had more than 1 type of vascular lesion. Additional organ manifestations were eye involvement in 32 , central nervous system involvement in 4 and gastrointestinal involvement in 3 patients. All but one patient used IFX at a dose of $5 \mathrm{mg} / \mathrm{kg}$ every $6-8$ weeks. All patients used concomitant prednisolone and 51 received pulse methylprednisolone during induction. Other concomitant medications were azathioprine in 21 and mycophenolate mofetil in 4 patients. Outcome of IFX treatment at the end of a mean follow-up of 25.9 months (range 1-103) is tabulated according to arterial and venous involvement (Table 1). Overall, $57 / 83$ (68\%) patients obtained remission with no further relapses and IFX could be stopped in $12(14 \%)$ of them. IFX was discontinued due to adverse events in 15 patients. These were allergic reactions in 8 , tuberculosis, disseminated zona, lung adenocarcinoma, fibromyxoid sarcoma, heart failure, systemic lupus erythematosus, and palmoplantar pustulosis in 1 patient each. Three patients had died. Causes of death were lung adenocarcinoma in one patient and pulmonary hypertension related right heart failure due to pulmonary artery thrombosis in 2 patients.

Conclusion: Infliximab seems to be beneficial in Behçet syndrome patients with vascular involvement, even in those who are refractory to immunosuppressives and corticosteroids. No further relapses occurred in $68 \%$ of the patients, and adverse events leading to discontinuation were observed in $18 \%$.

Disclosure of Interests: None declared

DOI: 10.1136/annrheumdis-2021-eular.3971

Table 1.

\begin{tabular}{|c|c|c|}
\hline & Arterial Involvement $(n=36)$ & Venous Involvement $(n=47)$ \\
\hline Main reason for infliximab use & $\begin{array}{l}\text { Pulmonary artery aneurysm and/or thrombosis, } n=29 \\
\text { Peripheral artery aneurysm, } n=4 \\
\text { Aortic aneurysm, } n=3\end{array}$ & $\begin{array}{l}\text { Vena cava superior and/or inferior thrombosis, } n=5 \\
\text { Lower extremity } D V T, n=24 \\
\text { Budd-Chiari syndrome, } n=4 \\
\text { Intracardiac thrombosis, } n=2 \\
\text { Dural sinus thrombosis, } n=7 \\
\text { Leg ulcer, } n=5 \\
\text { Previous treatment }\end{array}$ \\
\hline First line infliximab & 4 & 13 \\
\hline Corticosteroids & 34 & 38 \\
\hline Cyclophosphamide (CYC) & 25 (15/25 refractory to CYC; $10 / 25$ for maintenance after CYC) & 11 (8/11 refractory to CYC; $3 / 11$ for maintenance after CYC) \\
\hline Interferon-alpha & - & 13 \\
\hline Azathioprine & 21 & 17 \\
\hline Mycophenolate Mofetil & 1 & 2 \\
\hline Cyclosporine A & - & 2 \\
\hline $\begin{array}{l}\text { None due to non-compliance } \\
\text { Outcome }\end{array}$ & 2 & 1 \\
\hline Remission, still on infliximab & 16 & 23 \\
\hline Discontinued due to remission & 4 & 8 \\
\hline Discontinued due to adverse events & 5 & 9 \\
\hline Discontinued due to relapse & 5 & 3 \\
\hline Discontinued due to non-compliance & 5 & 3 \\
\hline Died & 2 (1 had previously discontinued due to relapse) & 1 \\
\hline
\end{tabular}

